\title{
Erratum to: Metalloproteinases regulate CD40L shedding from platelets and pulmonary recruitment of neutrophils in abdominal sepsis
}

Milladur Rahman • Jonas Roller • Su Zhang • Ingvar Syk •

Michael D. Menger • Bengt Jeppsson • Henrik Thorlacius

Published online: 22 May 2012

(C) Springer Basel AG 2012

Erratum to: Inflamm. Res. (2012) 61:571-579

DOI 10.1007/s00011-012-0446-6

The original version of this article unfortunately contains a mistake in the Result section at "Inhibition of MMPs protects against septic lung injury": Administration of GM6001 decreased CLP-induced lung wet:dry ratio from $5.4 \pm 0.1$ to $\mathbf{4 . 6} \pm 0.1 \ldots$

The online version of the original article can be found under doi:10.1007/s00011-012-0446-6.

M. Rahman · J. Roller $\cdot$ S. Zhang $\cdot$ I. Syk ·

B. Jeppsson · H. Thorlacius $(\square)$

Department of Clinical Sciences, Malmo, Section of Surgery,

Skåne University Hospital, Lund University,

20502 Malmö, Sweden

e-mail: henrik.thorlacius@med.lu.se

J. Roller · M. D. Menger

Institute for Clinical and Experimental Surgery,

University of Saarland, Homburg/Saar, Germany 